\title{
Mineral carbonation of sedimentary mine waste for carbon sequestration and potential reutilization as cementitious material
}

\begin{abstract}
This study highlights the importance of mineralogical composition for potential carbon dioxide (CO2) capture and storage of mine waste materials. In particular, this study attempts to evaluate the role of mineral carbonation of sedimentary mine waste and their potential reutilization as supplementary cementitious material (SCM). Limestone and gold mine wastes were recovered from mine processing sites for their use as SCM in brick-making and for evaluation of potential carbon sequestration. Dominant minerals in the limestone mine waste were calcite and akermanite (calcium silicate) while the gold mine waste was dominated by illite (iron silicate) and chlorite-serpentine (magnesium silicate). Calcium oxide, $\mathrm{CaO}$ and silica, $\mathrm{SiO} 2$, were the highest composition in the limestone and gold mine waste, respectively, with maximum $\mathrm{CO} 2$ storage of between 7.17 and $61.37 \%$. Greater potential for $\mathrm{CO} 2$ capture was observed for limestone mine waste as due to higher $\mathrm{CaO}$ content alongside magnesium oxide. Mineral carbonation of the limestone mine waste was accelerated at smaller particle size of $<38 \mu \mathrm{m}$ and at $\mathrm{pH} 10$ as reflected by the greater carbonation efficiency. Reutilization of limestone mine waste as SCM in brick-making exhibited greater compressive strength and lower water absorption compared to the bricks made of gold mine waste. The gold mine waste is characterized as having high pozzolanic behaviour, resulting in lower carbonation potential. Therefore, it has been noticeable that limestone mine waste is a suitable feedstock for mineral carbonation process and could be reutilized as supplementary cementitious material for cement-based product. This would be beneficial in light of environmental conservation of mine waste materials and in support of sustainable use of resources for engineering construction purposes.
\end{abstract}

Keyword: Carbon sequestration; Climate change; Carbon capture and storage; Mine waste; Mineralogy 